\title{
Blended Collaborative Learning Supporting Pedagogy Students' Reflective Practice
}

\author{
Niki Lambropoulos, Charikleia Pitsou \\ Department of Education \& Social Work Sciences, University of Patras, Patras, Greece \\ Email: niki.lampropoulou@upatras.gr,xpitsou@upatras.gr
}

How to cite this paper: Lambropoulos, N., \& Pitsou, C. (2020). Blended Collaborative Learning Supporting Pedagogy Students' Reflective Practice. Creative Education, 11, 1930-1946.

https://doi.org/10.4236/ce.2020.1110141

Received: September 10, 2020

Accepted: October 17, 2020

Published: October 20, 2020

Copyright (อ 2020 by author(s) and Scientific Research Publishing Inc. This work is licensed under the Creative Commons Attribution International License (CC BY 4.0).

http://creativecommons.org/licenses/by/4.0/ (c) (i) Open Access

\begin{abstract}
Educating the pedagogy students as teachers is one of the main aims of the Department of Education and Social Work Sciences, University of Patras, Greece. Teachers in Reflective Practice is a compulsory module; groups of 20 students are obliged to shadow teachers at the schools for reflective practice, active engagement in the educational activities and teachers' shadowing, reflective meetings with the tutors and students' final assignments. The aim of the intervention was to advance and modernize the module with new pedagogical methods and associated tools widely available to the tutors and the students. Following the literature review and the current trends in university students' education, collaborative and flipped classroom learning supported by both an online course and an onsite course was decided to be implemented in addition to their involvement in the school. The research design and methods followed mixed-methods research design for validation and generalization. As such, the findings derived from an online questionnaire, the eClass logs, a focus group discussion, and tutors' observation notes are presented and discussed. It appears that reflective engagement and accelerated learning were evident; the online course and discussions were utilized for active engagement; lastly, digital literacy and more time in the classroom are needed for better results. As a result, the implications and best practices are extracted for similar reflective practice courses.
\end{abstract}

\section{Keywords}

Reflective Practice, Blended Learning, School Education, CSCL, E-Learning, Flipped Classroom, Shadowing

\section{Pedagogy Students' Education as Reflective Practitioners}

Students as reflective practitioners could not be a non-productive compulsory 
process that occurs during university teacher training but a meaningful educational process that will enable the students to actively participate in professional learning practice and teachers' communities, whilst developing collective and individual skills such as creativity, critical thinking, collaboration, peer learning, and educational reflection. That is, they are given the opportunity, through practical training, to perceive in practice what they have learned, but also their own value, opinions, and limitations (Ball \& Forzani, 2009). During the internship, all students are required to transform and convert the theoretical knowledge they have acquired during their years of study into practice. They are required to respond to three dimensions that are practical, technical, and empirical. These three dimensions require both theoretical training and an interpretative approach to enable the future teacher/student to answer individual aspects about their own teaching: design lesson plans; reflect, evaluate and correct their own work and evaluation ability. For critical thinking, the future teacher deals with the application of rules as well as undocumented forms of action in school reality, and furthermore, as a reflective designer he enables and manipulates the learning process conditions (Chrysafidis, 2014).

Critical reflection requires teacher candidates to continually examine their own thoughts, perspectives, biases, and actions. Reflective practice facilitates the development of new knowledge, skills, and dispositions in teacher candidates by fostering critical contemplation of actions in a real-world environment as in a related field experience in a K-12 school (Slade et al., 2019). As a reflective practitioner (Schon, 1983, 1987) the teacher/student engages in reflective thinking that originates in doubt, hesitation and embarrassment, situations that lead to new searches, through the recall of relevant knowledge and experience (Spalding \& Wilson, 2002). Reflection on educational practice is considered not only an integral part of the educational process but also a key factor in identifying, analyzing, and solving complex problems. However, acquiring the ability to reflect is not an easy task, even for experienced teachers.

Many studies have been conducted for reflective practice for students in pedagogy. Kettle \& Sellars (1996) studied the development of third-year teaching students. Gibbs (1988) suggests that individuals develop analysis of feelings and evaluation of experience. According to Bartlett (1990), becoming a reflective teacher involves moving beyond a primary concern with instructional techniques and "how to" questions and asking "what" and "why" questions that regard instructions and managerial techniques not as ends in themselves, but as part of broader educational purposes.

In a need to advance and modernize the module, an online course was designed and developed. The new technologies available were the eClass university learning management system and the students' devices. Hence, the initial research questions were formulated as follows:

1) In what ways eLearning and new technologies can aid students' onsite reflective practice? 
2) In what ways pedagogical methods can be effective utilizing these new technologies to advance students' onsite reflective practice?

Open eClass is a free course management system created by the Asynchronous E-Learning Team of the Greek Academic Web GUnet (The Greek Universities Network) and installed and used by many Greek academic institutions. The UPatras eClass platform (https://eclass.upatras.gr/) follows the philosophy of open source software and supports the Asynchronous eLearning service without restrictions and commitments. The service can be accessed using a simple web browser without the need for specialized technical knowledge.

This article discusses the need for the eLearning and new technologies introduction at the pedagogy students' reflective practice and the associated pedagogical approaches and methodologies to advance their reflective practice both onsite and online. The proposed flipped classroom approach is anchored in collaborative onsite and eLearning partnerships in small groups as well as pairs as the blended learning approach to support their reflective practice. The case study presents results from the intervention to advance the traditional reflective practice model.

\section{The Need for eLearning and New Technologies}

Education is generally acknowledged as one of the crucial components of personal and professional development. The integration of Information and Communication Technology (ICT) in education as well as the social and collaborative nature of the Internet provided another medium for communication and training. In his foreword for the United Nations Educational, Scientific and Cultural Organization (UNESCO) report (2002), Daniels said that within a short time ICT has become one of the basic building blocks of modern society. Furthermore, the current shift occurring in the Web from a static content environment where end users are the recipients of information-defined as Web 1.0-to one where they are active content creators-defined as Web 2.0-can be described as a transition to a more distributed, participatory, and collaborative environment (Delich, 2006). Web 2.0 is a platform where "knowledge-working is no longer thought of as the gathering and accumulation of facts, but rather, the riding of waves in a dynamic environment" (Downes, 2005).

UNESCO suggests that countries need to keep pace with technological development and the changing competencies. Economic advantage will accrue to a population that acquires competencies in processing information into knowledge and applying it in work and everyday life. These competencies are not only related to using the devices but also working on procedures that give access to information and skillfully transforming information into knowledge. As this is the task of the educator, educational systems will become a national resource as important as the traditional factors of production-land, labor, and capital. This in turn would cause educators to become more important, their productivity and their wages should increase, but they can also expect the nature of their jobs to 
change with a great deal of specialization (UNESCO, 2002: 633-640).

ICT is the backbone of the knowledge economy and has been recognized as an effective tool for promoting economic growth and development (World Bank Report, Chen \& Kee, 2005). Despite the expansion of ICT, general access to ICT varies across continents, and countries even within the same continent, indicating a digital divide (Reddy \& Manjulika, 2002). Organizations, educational institutions and business have been investing in the use of ICT in Education, or what is now called Technology Enhanced Learning (TEL). E-Learning is a component of TEL and describes learning via the Internet, intranet, and extranet. The freedom that e-learning offers, and the increasing number of online courses provided by educational organizations offer new opportunities for personal and professional development in a life-long learning course (Lambropoulos \& Romero, 2015).

To decide upon the pedagogical frameworks utilizing the new technologies a literature review suggested that for the past 50 years two main trends have been observed in education, namely the socio-cultural focus and the use of technology. However, these two trends have evolved almost separately. Several innovative pedagogical approaches, models and tools aim to acknowledge that the development of new technologies increasingly relies on an appreciation of the social circumstances in which systems are used. In this context, educational design is the systematic processing of activities to solve an instructional problem with the aid of technologies. Nonetheless, the e-learning systems were found to be information-based. For these reasons, they fail to support e-learners' transition between internalization to externalization of knowledge and skills and becoming active participants in their own growth. So, if a blended learning approach is implemented where onsite and online learning were appropriate, there is a possibility to understand collaborative practice, university students' learning and teaching quality could be improved. Therefore:

- Information technologies aid and respond to students' individual abilities and needs.

- Students who do not actively participate in the onsite teaching and learning can be encouraged using information technologies.

- E-Learning helps to fill the gaps that may exist in learning.

- By using them the students dare and experiment at their own pace.

- The availability of multimodal sources of information and educational material contributes to both tutors and students by revising the educational approaches.

- Blended learning approaches offer the opportunity for effective and efficient collaborative learning.

A modern blended learning approach is the flipped classroom. Chouli (2015) applied a flipped classroom approach to teach English for Special Purposes to Marine Engineering Students. She reported changes in learners' attitudes towards English language as well as enhancement of vocabulary development and 
communication competence.

A flipped learning course has been implemented in a Department of Education at the University of Patras, a peripheral Greek University (Plota \& Karalis, 2019). Plota's and Karalis' intervention was the first official attempt to apply the flipped classroom approach in a Greek University. The authors refer to another attempt which surfaced during the literature review that took place in a higher education institution, the Merchant Marine Academy of Chios. The authors followed the flipped classroom organization in a similar Greek context and found similar results about the overall satisfactory experience, good organization of a course and overall improvement of their students' active participation in the whole process. They concluded that the first findings record high satisfaction rates; their students suggested that flipped classrooms contributed to a better comprehension of the course content, enhanced their active participation, and promoted their critical thinking abilities.

Due the fact that the Pedagogy students work in small groups and pairs, they were randomly divided into groups to attend the school classes for one week for each group. They had to shadow and observe the teachers in each classroom in pairs, also keeping observation notes about specific thematic educational subjects. Therefore, collaboration and pair reflection were a critical part of the intervention.

\section{Collaborative Onsite and eLearning Partnerships: Small Groups and Pairs}

Other than the methodology, this is the flipped classroom, the specific pedagogical approach needed $t$ be in place for flipped classroom to be effective. Reflective practice occurs in the head of each individual student and needs to be externalized and discusses with their peers. In fact, cognition is a complex social phenomenon that occurs within the individual's head (Lave, 1988:1). It refers to intermediate variables that describe social interactions and their relationships with the conditions that facilitate learning. Because the intermediate variables are invisible, their observation and study are difficult. However, it is possible to study human activity and inference from this cognitive change. Activity in the form of discussion of shared experience has been considered an effective means for adult learning (e.g. Brown \& Duguid, 2000). Other than the importance attached to socio-cultural learning, collaborative learning as well as passive and active participation are concepts related to university teaching and learning. Mezirow (2000), in his theory of transformative learning, proposed that adults were reflective, critical, and open to others' opinions; thus, active participation in groups was essential.

Two terms have been used interchangeably in collaborative learning history: cooperation and collaboration. Cooperation was the basis of sociability "acting together, in a coordinated way at work, or in social relationships, in the pursuit of shared goals, the enjoyment of the joint activity, or simply furthering the rela- 
tionship" (Argyle, 1991:15). (Johnson \& Johnson, 1994 provide an overview on cooperative learning.) An attempt to propose a distinction between cooperation and collaboration was made by Teasley and Roschelle (1993:235): Collaboration is a coordinated, synchronous activity that is the result of a continued attempt to construct and maintain a shared conception of a problem. Cooperative work is accomplished by the division of labor among participants, as an activity where each person is responsible for a portion of the problem solving. UNESCO's definition embraces most of the concepts; collaborative learning occurs when learners work in groups on the same task simultaneously, thinking together over demands and tackling complexities.

Collaboration is the act of shared creation and/or discovery. Within the context of electronic communication, collaborative learning can take place without members being physically in the same location. (Technology \& Learning definitions, UNESCO (n.d.)). Thus, shared creativity for new knowledge building is the ultimate collaboration learning target that can also be expanded to online settings. Working on shared tasks implies university students' participation and engagement.

According to Dillenbourg and colleagues (1996), the key to supporting collaboration is to find suitable intermediate variables to describe and support collaborative interactions and their relationships with the conditions that facilitate collaborative learning. Dillenbourg and colleagues suggested that the development of an understanding of collaborative learning began with the learner as an individual; then it moved to group learning in a more socio-cultural mode, and finally, expanded to the community. During the 70 s and early 80 s, research was focused on the individual's learning processes. The context of their interaction was a backdrop rather than the focus of research. When the group became the unit of analysis, the focus shifted to the social construction of knowledge; however, this was still based on studying individuals. In terms of empirical research, the focus was on comparative processes to establish whether and under what circumstances collaborative learning was more effective than learning alone. Because collaborative learning is inherently complex, it was almost impossible to establish causal links between the conditions and the effects of collaboration. In Piaget's early writings (1932), the potential productivity of peer interaction in relation to cognitive development was related to the achievement of concrete operational modes of thought in the early years. Egocentrism was the main obstacle to operational thinking and required its "decentralization". This is the ability to consider multiple points of view and multiple covering factors in a given situation. One of the fundamental concepts that helped collaborative learning to evolve was the socio-cognitive conflict derived from the interaction with other learners as a result of decentralization.

Lastly, shadowing is the process of following a student or educator through one day, part of a day, or longer, experiencing what that person experiences for the purpose of professional learning (Soguero et al., 2015). It is a subject-centered 
structured observation and, in this sense, allowed the student to follow teachers' activities to observe, analyze and criticize their approaches. Teachers can be regarded as "shadowers" who gain clarity and awareness into the everyday educational challenges.

After a week of shadowing and taking observation notes onsite, the students had to exchange and discuss about their observations on the thematic subjects (e.g. pedagogical approaches, specific students' behavior, timetable, class climate etc.). As such, the both onsite and online teaching and learning took place as a blended method to advance the students' reflective practice.

\section{Blended \& Flipped Learning to Support Pedagogy Students' Reflective Practice}

Blended Learning incorporates both synchronous and asynchronous learning methods (Mystakides \& Lambropoulos, 2014). In modern learning, teachers and students share the element of time. Contemporary learning refers to learning in which students and teachers interact simultaneously with the same classroom or using the same web interface (e.g. Netmeeting, chat, etc.). Asynchronous learning (Berge \& Collins, 2006; Steiner, 1996) is a learning exchange between trainees and the teacher or between trainees themselves, which takes place independently of time and space. It refers to open and distance learning, when learning participants interact indirectly with each other using communication tools such as emails, bulletin boards, e-learning materials, etc.

Blended Learning refers to the integration of new technologies into the learning environment which increases the effectiveness and efficiency of learning as well as maximizes the value of the lesson. The embedded content combines modern and asynchronous content within the real-world classroom environment and the computer virtual environment. The computer acts as another tool, just like books or a table and cannot replace the teacher in any way. Face-to-face, online, and onsite are the three types embedded.

There are several reasons for using Blended Learning (Lambropoulos, 2004), as it:

- Hosts various forms of learning

- Supports learning using more than one (multi-sensory) senses

- It enhances all elements of the educational process

- Encourages students' participation in the learning process through self-expression

- Improves students' critical thinking

- Develops communication learning skills through interaction

- Facilitates social self-organized online learning

- Increases the motivation of students and teachers

Synchronous content requires the student and teacher to be together, just like

in the classroom. Examples of modern content are in the classroom and the virtual classroom. In both scenarios, participants and the 'leader' have a common 
time element. In the case of the physical classroom, the participants and the teacher also share a common position. Asynchronous content is a learning exchange between students and teacher that takes place independently of time and place, where:

- Students can examine the content according to their schedule.

- Students control the hierarchy of topics in which the content is examined.

- Students have time to think about the content.

- The asynchronous environment is of value to those who learn best by thinking about the content and those who can work in their own time and follow directions.

In Blended Learning both synchronous and asynchronous content are interchangeably utilized to accelerate learning. As such, Blended Learning:

- Provides various forms of learning with the option of choosing the most appropriate content and beginner solution.

- Supports flexibility.

- Takes advantage of the potential of this content and lesson.

- It is based on a multi-sensory approach and can be used to assimilate and apply knowledge.

- Improves criticism and induction thinking.

- Facilitates self-organizing learning. Students can learn in their own time in a safe environment.

- Makes learning enjoyable and relevant to students' interests.

Flipped Classroom (Bergmann \& Sams, 2012) was developed in the 1990s. Harvard professor Eric Mazur developed a "peer-to-peer" model that provided material for students to prepare and reflect before class. and then used the classroom to encourage deeper cognitive thinking through interaction with each other and teacher challenge. This "classroom reversal" provides a learning environment for personalized guidance and guidance (Lage, Platt, \& Treglia, 2000). Providing students with the material to gain a basic level of knowledge and understanding prior to the classroom, teaching time can be used to deepen learning and develop higher-level cognitive skills, moving students away from passive learning and active learning. and in addition to their collaborative and problem-based learning. Thus, the teacher orchestrates learning activities that make it easier for students to gain control of their own learning in self-organized learning management through personalized assessment.

True innovation in the classroom will depend on how it is designed, as the aim is to "educate technology rather than digitalizing the classroom" (Prensky, 2010). Jonathan Bergmann and Aaron Sams developed the model in 2006 in the Secondary School of Woodland Park, Colorado, where both worked as teachers (Bergmann \& Sams, 2012). Flipped classrooms were found to offer opportunities for students to develop critical and independent thinking, self-organized and collaborative learning by interacting collaboratively with peers. Moraros et al. (2015) and Blair et al. (2015), describe it as the action that helps students to im- 
prove their academic results. The Flipped Learning Network (2012), produced a report showing that from the 453 professors that applied the flipped classroom, $67 \%$ perceived an improvement on the academic results of their students, $80 \%$ noticed an improvement on the attitude of their students, and $99 \%$ stated that they would "flip" their classrooms again. Furthermore, Yarbro et al. (2014) found that the performance of students improved, and both teachers and students were more satisfied with the teaching process and outcomes.

It appears that the model does improve the academic performance of students as well as their engagement with the learning process (Flores et al., 2016). According to the researchers, the student ceases to be a passive element and develops key competencies such as: selection of information, teamwork, critical thinking, and self-management and self-assessment of the learning process. Additionally, the teacher mediates, offers support, and guides. The study points to the fact that the flipped classroom improves integration of concepts; participation and communication; students' interest in the course; integration of ICTs in the classroom; and academic results. Besides, the model allows for a change in the roles of both professors and students.

The following model (Figure 1) is a process visualization of the proposed model. The students follow a circle of reflective practice activities both online and onsite.

The research questions were more focused:

1) In what ways eLearning and available new technologies such as students' mobiles can aid and modernize students' reflective practice?

2) In what ways collaborative learning and flipped classroom can be effective utilizing these new technologies to advance students' onsite reflective practice?

3) Will the students embrace this intervention?

The students follow a collaborative learning for flipped classroom process that blends open and distance learning and onsite shadowing keeping diaries of reflection.

This intervention at the Department of Education and Social Sciences took

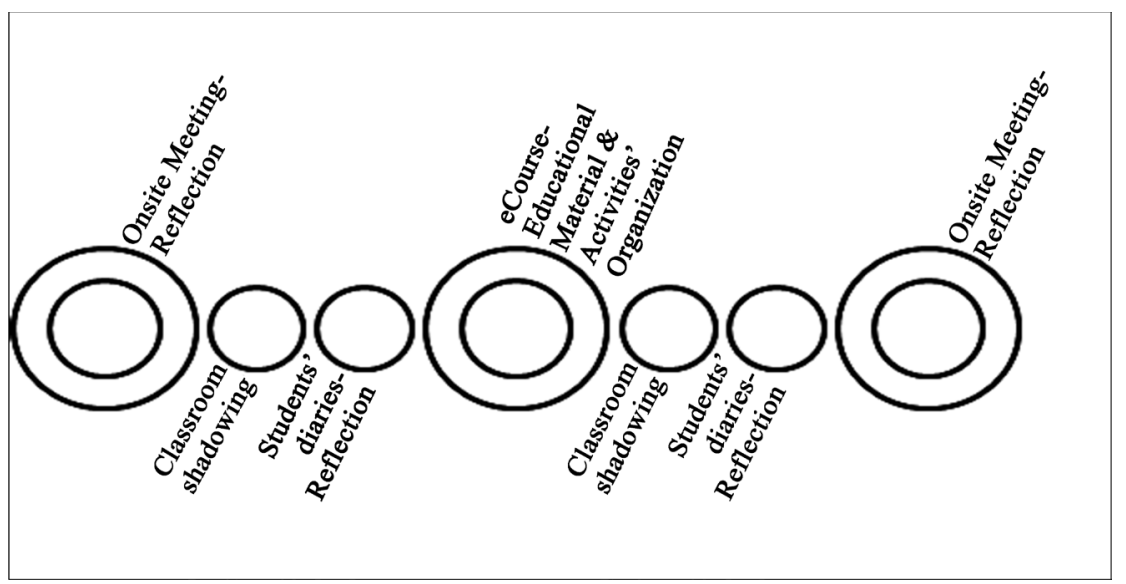

Figure 1. Blended learning reflective practice. 
place during the $7^{\text {th }}$ Semester Practice following the blended and flipped classroom approaches; 169 university students were registered in the online course. The course organization, the instructions and the educational material was provided via the course on eClass. The students were also divided into small teams, this is 10 students average for each group for teachers' shadowing. They had the work collaboratively via both asynchronous eLearning using eClass and synchronous Skype for Business for teleconferencing, and onsite, this is the school classrooms. Authentic practice in real working conditions acts as a bridge between the university environment and the role of a student and the real working environment with the engagement and responsibility of a professional. The tutors kept observational notes along with students' peer observation and feedback. Such authentic practice may also act as a test for the students to discover whether they are really interested in the teachers' profession.

\section{Research Design, Methods \& Findings}

During the $7^{\text {th }}$ Semester 2019,169 university students were registered in the online course and were randomly assigned in blended learning partnerships, such as small groups and pairs. The case study research intervention conducted was anchored in quantitative and qualitative research employing the following instruments: 1) a questionnaire at the end of the intervention with closed and open-ended questions, 2) a focus group of 5 randomly selected students was conducted to acquire the students' opinions about the advantages and disadvantages of the intervention, 3) logs and statistics provided by the eClass, and 4) tutors' observation notes at the university teachings. In research fieldwork (Button, 2000; Suter, 2000), it is important to consider how relevant people do what they do, that is the "interactional what" of their activities. This is the explication of subjects' prior knowledge, this is what people must know to do work, and how that knowledge is deployed in the ordering and organization of work.

Eighty-five (85) out of 169 last year pedagogy students freely responded to the online questionnaire. The average age was 22 years old.

An online 4 Likert scale questionnaire was utilized to extract a clear view on positive and negative responses. Out of 85 responses, the majority of the students $(88.2 \%, \mathrm{~N}=75)$ were between 18 and 22 years old, $9(10.6 \%)$ between 23 and 40 years old and $1(1.2 \%)$ over 51 years old. Most were women $(84.7 \%, \mathrm{~N}=$ 72 ) and 13 (15.3\%) men; 51 (60\%) from urban areas, 23 (27.1\%) from semi-urban areas and $13(15.3 \%)$ from rural areas. Most of the students ( $94 \%, \mathrm{~N}=80$ ) were undergraduates, whereas $4(5 \%)$ hold a second degree, and 1 (1\%) had acquired a master's degree already.

The data were collected from the online questionnaire, the eClass logs, the students' observations and opinions and the tutors' observation notes. Such triangulation provided the necessary validity of the case study toward generalization of the results. 


\subsection{Quantitative Findings}

According to the eClass logs, 141 students were registered online on the Reflective practice online class. There were 9 students' groups. Their overall visits were 8384, the total number of page views were 34,877 , and there were 2056 total hours online. Most of the online presence and accessing the educational material were during the months October 2019 and January 2020. Most of their visits and page views were related to accessing the educational material (37.8\%), the educational sections area $(25.2 \%)$ and the assignments area (19.6\%). They did not use the forums much.

On the question about the new blended learning reflective practice, more than half of the students provided a positive response $(95 \%, \mathrm{~N} 81)$ and only $5 \%$ disagreed $(\mathrm{N}=4)$. The majority $81(95 \%)$ of the students suggested that the cooperation with the coordinating tutors was successful.

On the question about the flipped content, 53 (86\%) suggested that the content was clear and well organized whereas $12(14 \%)$ disagreed. On the question about collaborative active observation and shadowing, the majority $(85 \%, \mathrm{~N}=$ 72) of the students agreed that it was effective and 13 (15\%) disagree. Overall, most of the students $(78 \%, \mathrm{~N}=66)$ responded that they thought their own reflective practice was productive whereas $22 \%(\mathrm{~N}=19)$ were negative.

Regarding the overall effectiveness of onsite meetings to discuss both the reflective practice experience and the flipped educational material, most of the students $(73 \%, \mathrm{~N}=72)$ found these meetings very effective. Also, the actual discussion in the onsite meetings was found very effective by $73(86 \%)$ students. On the actual reflective practice discussion most of the students also suggested that it was overall effective $(83 \%, \mathrm{~N}=71)$. The students had to write a final assignment about the reflective practice. Most of them $(81 \%, \mathrm{~N}=70)$ suggested that the final assignment was helpful with the educational process. In total, most of the students found the overall reflective practice effective ( $90 \% \mathrm{~N}=76)$.

Most of the students $(90 \%, \mathrm{~N}=76$ ) advocated working in collaborative eLearning and onsite partnerships and in small groups and pairs in particular; there were no responses to totally negative experiences. In comparison to the previous results of absence of very negative responses, working in pairs appeared to be effective with $13(15 \%)$ to disagree and $5(6 \%)$ to totally disagree. Similar responses referred to the online groups, with $12(14 \%)$ negative responses and 1 (1\%) totally negative response.

On the question about the learning management system eClass, many students $(32 \%, \mathrm{~N}=27)$ found that it was not so helpful whereas the majority $(62 \%$, $\mathrm{N}=66 \%$ ) found it useful. The overall eClass use and students' experience was rather satisfactory as $34(40 \%)$ suggested they had an unsatisfactory experience.

To sum up, the students suggested that the overall course and the way they experienced it was very satisfactory and useful $(91 \%, \mathrm{~N}=78)$.

\subsection{Qualitative Findings}

The questionnaire open questions responses were coded, and quantified qualita- 
tive analysis was conducted. There was also a small online focus group of $5 \mathrm{stu}-$ dents randomly selected.

The qualitative results were extracted from the open-ended questionnaire questions and were quantified. In regard to the positive points on the collaborative learning partnerships in regard to small groups collaboration, the majority of the students responded with positive comments about the collaboration with strangers; then reflective discussion and feedback with their co-students; faster and easier communication as well as support and meeting new people. There were only 3 comments on both the negative students' experience reporting that the collaboration with a stranger was absent or overall difficult.

Compared to onsite learning, the students answered a question about the eLearning benefits. Most students suggested that guidance and support via eLearning was more immediate (32.3\%), similarly to immediate and clear communication (19\%), effectiveness (16\%) and overall speedy organization (12\%), as for example the questions answered in the forum so everyone could see the answers at any time (8\%). Regarding the eLearning disadvantages, nothing (57\%) was the most coded response. Responding with similar questions and information $(17 \%)$ as well as changing the initial instructions were the most quoted responses (10\%).

The focus group discussion was analyzed, and quantified qualitative analysis was conducted. Positive students' comments were the following:

Subject A: The collaboration was good, excellent I would say. We did not have any problems to study and communicate together... We successfully completed the work and I personally had a satisfactory feeling with the result.

Subject B: The organization and communication were much better... My team was focused on the students with special needs... I didn't like the online communication compared to the real communication but there are no options these days... The communication with the tutors was enjoyable.

Subject C: We were a small group of 5 students, and we managed to get from the theory to the actual practice. We collaborated, if one had a different opinion, we discussed about it and kept it or deleted it or even corrected the issue. The collaboration was superb without tensions. The internet connection was not that good, and we worked with material both online and onsite...

Subject D: Working with the internet was easier, we divided the tasks and each one worked on the allocated task.

Subject E: We had fun and by coincidence I did know the students in my group. Collaborative work and learning are more fun. Collaborative eLearning was also fun as we had to work and organize from a distance.

As for the disadvantages, the 2 most reported problems were working with strangers and difficulty to collaborate with strangers online.

\subsection{Tutors' Observation Notes at the University Teachings}

According to tutors' observation notes, although the flipped classroom model 
was overall successful, the students did not use their mobiles, laptops and tablets in the classroom although they were very active when it comes to social media i.e. they are used to use the applications for educational purposes. Initially, they were reluctant to actively participate in the reflective practice in the actual classroom even though the learning partnerships were observed to be very successful. However, when a couple of students started talking about the experiences and the educational material most students followed the discussion. Regarding the technology utilization, the low impact of technology was raised from the tutors' observation of a mismatch among the students' way of tools use and the functions for which the developers had planned them. In other words, the students did not fully utilize the tools available in eClass and the actual use in the onsite meetings in the classroom.

\section{Discussion}

There has been a shortage of research and examples on using the exact synthesis of pedagogical approaches, these are open and distance learning and flipped classroom as part of blended learning in reflective practice and collaborative learning in learning partnerships for students as teachers' reflective practice.

In this study, the results suggest the following: the overall course and the way the students experienced it was very satisfactory and useful; the new model based on blended learning reflective practice organization cooperation with the coordinating tutors was successful; the content was clear and well organized; the collaborative active observation and shadowing was a helpful reflective practice experience; own reflective practice and flipped educational material were productive both in online and onsite meeting discussion; lastly, the final assignment was helpful with their own educational process as professional teachers. In the open questions, there were positive comments on the collaborative learning partnerships and the collaboration with strangers, reflective discussion, and feedback, faster and easier communication, better support and meeting new people. However, some students suggested that collaboration with a stranger and absent or difficult collaboration was difficult.

In addition, students believed that the eClass helped with the overall course organization, the guidance and support was more immediate similarly to immediate and clear communication, effectiveness, and overall speedy organization. For the questions answered in the forum so everyone could see the answers at any time.

Fidalgo-Blanco et al. (2017) worked on a blended learning course, synthesizing both the online and onsite environment using micro-flip teaching. In their findings it is reported that knowing a subject prior to being taught in class is a great advantage. With the MFT method, students can learn the subject theoretically before class. The method focuses responsibility on the students and enables them to apply what they have learned through classroom activities and concepts. In addition to knowing the subject, students can reflect on it and apply it to a 
real situation, which corresponds to cognitive development. Students suggested the importance and flexibility of accessing content when it is desired and as many times as necessary. Yilmaz (2017) found that e-learning readiness and its subfactors such as self-efficacy, internet self-efficacy, online communication self-efficacy, self-directed learning, learner control and motivation towards e-learning are predictors of student satisfaction and motivation. Online communication self-efficacy has positively affected satisfaction and motivation towards the course in FC model of instruction. According to Sohrabi \& Iraj (2016) reported more communication with the instructor and that the flipped classroom can be implemented for different groups of students and can be used to improve the learning experience. Overall findings indicate that students need to be engaged in learning, looking for new ways and environments different from the lecture-style classes. Although the students did not use it as much as expected, a forum for questions associated with classroom activities, thus attempting to minimise the time needed to answer any questions is significant (Fidalgo-Blanco et al., 2017).

Following the observation notes, tutors' observation notes were similar to Johnson (2013). There is a frequent concern about the flipped classroom model is that it widens the digital divide. Students who have access to digital devices will over-perform students that have less access to digital devices. Also, the flipped classroom is a new form of lecturing, lectures are considerably shorter, and students can watch them at their own pace in desired time and place or with learning partners.

Overall, the overall results follow the recent research findings from similar blended learning flipped classroom implementations: it is overall helpful and satisfactory students' experience; organization, communication, collaboration and support between the students in their learning partnerships and with the instructors is immediate and more effective; e-learning readiness is an important predictor of satisfaction and motivation for flipped classroom implementation models; and it can be used in more diverse forms and circumstances that have been implemented in the past by different researchers.

\section{Conclusion and Future Work}

The aim of this article was to present a new model of the Reflective Practice course in a Greek University that prepares a working force of teachers. Teachers in Reflective Practice is a compulsory course provided to the last year students divided into: 1) an eLearning course; 2) groups of 20 students for one week of reflective observation and practice in the classroom; 3) assistance teaching and active engagement in the educational activities; 4) reflective meetings for each group with the course teachers; and 5) each student's final assignment on reflective practice. Based on solid theoretical frameworks, the tutors implemented a new model based on a blended learning approach; this is Open and Distance Learning as well as onsite teaching and learning. Flipped classroom and colla- 
borative learning were engaged for educational organization and studying via the eLearning course in one reflective meeting where students used their own mobiles for reflective engagement. The sequence of the activities prepared in the online course in the given week was followed by the relevant shadowing and educational activities and active reflective practice during the next in-class meeting. In this case study, the contextual factors were considered as there was no control group to compare. In addition, the main Reflective Practice tutors are new at the University of Patras, so no previous experience was utilized for comparison. A mixed methods research design was implemented to conduct the actual research.

The results suggested that reflective engagement and accelerated learning were evident due to the blended approach, this is both the eClass course and the flipped classroom as well as the onsite collaboration and shadowing; also, mobile eClass access was utilized for active engagement; lastly, digital literacy and more time in the classroom are needed for better results. As a result, implications from the case study and best practices are provided for similar reflective practice courses. The model presented here is easily transferable because it minimizes the effort required for implementation and because of its ease of implementation and the effectiveness of the results. The students believed that the blended learning flipped classroom model aided in the overall course organization and it was overall successful. Following Fidalgo-Blanco et al. (2017) suggestion, such models may pose a problem in some cases because the administrative policies of the school or university may offer resistance to the idea of eliminating classroom hours and replacing these with other means such as eLearning partnerships and flipped classroom activities.

Therefore, other than the small-groups collaborative learning, peer learning was utilized for the pairing the students inside each classroom during shadowing. The students interacted with their pairs and learned from each other without any supervising authority in both formal and informal ways. They explored, discussed, explained, and criticized the classroom teaching and learning activities and developed skills in organization and planning, working collaboratively with others, giving and receiving feedback and evaluating their own learning.

These insights have the potential to fundamentally alter a teacher's view of students, the learning environment, and the teaching practices in their own classrooms. The aims were to grasp the classroom heterogeneous context and, simultaneously, to understand the work process and its relations. This back-andforth reflection was transcribed into classroom notes that were analyzed and discussed during our meetings with the students. The notes were clustered in categories and used for students' assignments.

However, more studies with experimental or control groups, pre-tests and post-tests need to be conducted to better validate the results and generalize the conclusions. In future work it may be interesting to investigate the factors that improve collaborative learning as such in blended learning and flipped class- 
room approaches. As such, more research needs to be conducted on the proposed model for better validation and generalization of the results and implications for university tutors in education and policy.

\section{Conflicts of Interest}

The authors declare no conflicts of interest regarding the publication of this paper.

\section{References}

Ball, D. L., \& Forzani, F. M. (2009). The Work of Teaching and the Challenge for Teacher Education. Journal of Teacher Education, 60, 497-511. https://doi.org/10.1177/0022487109348479

Bartlett, L. (1990). Teacher Development through Reflective Teaching. In J. C. Richards, \& D. Nunan (Eds.), Second Language Teacher Education (pp. 202-214). New York: Cambridge University Press.

Berge, Z. L., \& Collins, M. P. (2006). Perceptions of e-Moderators about Their Roles and Functions in Moderating Electronic Mailing Lists. Distance Education: An International Journal, 21, 81-100. https://doi.org/10.1080/0158791000210106

Bergmann, J., \& Sams, A. (2012). Flip Your Classroom: Reach Every Student in Every Class Every Day. International Society for Technology in Education.

Blair, E., Maharaj, C., \& Primus, S. (2015). Performance and Perception in the Flipped Classroom. Education and Information Technologies, 21, 1465-1482. http://link.springer.com/article/10.1007/s10639-015-9393-5

Button, G. (2000). The Ethnographic Tradition and Design. Design Studies, 21, 319-332. https://doi.org/10.1016/S0142-694X(00)00005-3

Chouli, A. (2015). Flipping a Merchant Class Around. Master Thesis, Patra: Hellenic Open University.

Chrysafidis, K. (2014). The Role of Practical Exercises in Creating Appropriate Conditions for the "New School". Research in Education. Hellenic Journal of Research in Education, 1, 89-106.

Fidalgo-Blanco, A., Martinez-Nunez, M., Borras-Gene, O., \& Sanchez-Medina, J. J. (2017). Micro Flip Teaching-An Innovative Model to Promote the Active Involvement of Students. Computers in Human Behavior, 72, 713-723.

https://doi.org/10.1016/j.chb.2016.07.060

Flipped Learning Network (2012). Improve Student Learning and Teacher Satisfaction with One Flip of the Classroom.

Flores, O., del-Arco, I., \& Silva, P. (2016). The Flipped Classroom Model at the University: Analysis Based on Professors' and Students' Assessment in the Educational Field. International Journal of Educational Technology in Higher Education, 13, 21. https://doi.org/10.1186/s41239-016-0022-1

Gibbs, G. (1988). Learning by Doing: A Guide to Teaching and Learning Methods. Oxford: Further Education Unit.

Johnson, G. (2013). Student Perceptions of the Flipped Classroom. Thesis for Master of Arts in Educational Technology, Vancouver: The University of British Columbia, the College of Graduate Studies.

https://open.library.ubc.ca/cIRcle/collections/ubctheses/24/items/1.0073641

Kettle, B., \& Sellars, N. (1996). The Development of Student Teachers Practical Theory of Teaching. Teaching and Teacher Education, 12, 1-24. 
https://doi.org/10.1016/0742-051X(95)00016-D

Lage, M. J., Platt, G. J., \& Treglia, M. (2000). Inverting the Classroom: A Gateway to Creating an Inclusive Learning Environment. The Journal of Economic Education, 31, 30-43. https://doi.org/10.1080/00220480009596759

Lambropoulos, N. (2004). From the Class to the e-Class and Back: Blended Learning in the Greek Schools. In the Proceedings of the 1st National Conference for the Use of ICT in Education. Scientific Society for the Valorization of ICT in Education.

Lambropoulos, N., \& Romero, M. (2015). 21st Century Lifelong Creative Learning. Hauppauge, NY: Nova Publishers.

Moraros, J., Islam, A., Yu, S., Banow, R., \& Schindelka, B. (2015). Flipping for Success: Evaluating the Effectiveness of a Novel Teaching Approach in a Graduate Level Setting. BMC Medical Education, 15, 1-10. https://doi.org/10.1186/s12909-015-0317-2

Mystakides, S., \& Lambropoulos, N. (2014). Playful Blended Digital Storytelling in 3D Immersive eLearning Environments: A Cost Effective Early Literacy Motivation Method. In Proceedings of the 3rd Workshop on Interaction Design in Educational Environments (pp. 97-101). Albacete. https://doi.org/10.1145/2643604.2643632

Plota, D., \& Karalis, T. (2019). Organization and Implementation of a Flipped Classroom Course in the Greek University Context. Educational Journal of the University of Patras, 6, 53-61.

Prensky, M. (2010). Digital Natives, Digital Immigrants. S.A.: Distribuidora SEK. Digital Natives, Digital Immigrants.

Schon, D. (1983). The Reflective Practitioner: How Professionals Think in Action. New York: Basic Books.

Schon, D. A. (1987). Educating the Reflective Practitioner: Toward a New Design for Teaching and Learning in the Professions. San Francisco, CA: Jossey-Bass.

Slade, M. L., Burnham, T. J., Catalana, S. M., \& Waters, T. (2019). The Impact of Reflective Practice on Teacher Candidates' Learning. International Journal for the Scholarship of Teaching and Learning, 13, Article 15. https://doi.org/10.20429/ijsotl.2019.130215

Soguero, M., Condon, D., Packard, C., \& Easton, L. B. (2015). Shadowing. In L. B. Easton (Ed.), Powerful Designs for Professional Learning (3rd ed., pp. 53-57). Oxford: Learning Forward.

Sohrabi, B., \& Iraj, H. (2016). Implementing Flipped Classroom Using Digital Media: A Comparison of Two Demographically Different Groups Perceptions. Computers in Human Behavior, 60, 514-524. https://doi.org/10.1016/j.chb.2016.02.056

Spalding, E., \& Wilson, A. (2002). Demystifying Reflection: A Study of Pedagogical Strategies That Encourage Reflective Journal Writing. Teachers College Record, 104, 1393 1421. https://doi.org/10.1111/1467-9620.00208

Steiner, V. (1996). What Is Distance Education. Distance Education Learning Resource Network (DLRN), Vol. 1, No. 1.

Suter, E. A. (2000). Focus Groups in Ethnography of Communication: Expanding Topics of Inquiry beyond Participant Observation. The Qualitative Report, 5, Article 1.

Yarbro, J., Arfstrom, K. M., McKnight, K., \& McKnight, P. (2014). Extension of a Review of Flipped Learning. Flipped Learning Network.

https://flippedlearning.org/wp-content/uploads/2016/07/Extension-of-FLipped-Learni ng-LIt-Review-June-2014.pdf

Yilmaz, R. (2017). Exploring the Role of e-Learning Readiness on Student Satisfaction and Motivation in Flipped Classroom. Computers in Human Behavior, 70, 251-260. https://doi.org/10.1016/j.chb.2016.12.085 